\title{
ALTERAÇÕES NO COMPORTAMENTO DAS ALGAS EUGLENAS GRACILIS NA PRESENÇA DE 17 $\alpha$ ETINILESTRADIOL E $17 \beta$ ESTRADIOL.
}

\author{
PINTO, L.H. ${ }^{1 *}$; SIERTH, R. ${ }^{2}$; SCHULTER, L.S. ${ }^{2}$; FAUSTO, M.C. ${ }^{2}$; SOARES, J.C. ${ }^{2} ;$ CIAMPO, L.D. ${ }^{3}$ \& ER- \\ ZINGER, G.S. ${ }^{4}$
}

\author{
1. Doutorando do Programa de Pós-Graduação em Saúde e Meio Ambiente da Universidade da \\ Região de Joinville - UNIVILLE \\ 2. Graduandas do curso de Farmácia da Universidade da Região de Joinville - UNIVILLE \\ 3. Ecobabitoga Tecnologia Ambiental \\ 4. Professor do Programa de Pós-Graduação em Saúde e Meio Ambiente da Universidade da Região \\ de Joinville - UNIVILLE \\ *Corresponding author: lucianoefar@gmail.com
}

\begin{abstract}
Pinto, L.H. ${ }^{1}$; Sierth, R. ${ }^{2}$; Schulter, L.S. ${ }^{2}$; Fausto, M.C. ${ }^{2}$; Soares, J.C. ${ }^{2}$; Ciampo, L.D. ${ }^{3}$ \& Erzinger, G.S. ${ }^{4}$, 2017. Alterações no comportamento das algas euglenas gracilis na presença de $17 \alpha$ etinilestradiol e $17 \beta$ estradiol. Braz. J. Aquat. Sci. Technol. 20(2). eISSN 1983-9057. DOI: 10.14210/bjast.v20n2. There is growing concern about contamination of water resources by "emerging pollutants". Endocrine interferons (EI) from pharmaceuticals, such as 17a-ethynyl estradiol and $17 \beta$-estradiol, fit this condition. This problem has been studied by researchers because little is known about the ecotoxicological risk of such compounds. There are several methods that aim to perform biomonitoring for the presence of Els previously mentioned, such as tests involving yeast or genetically modified fish. The disadvantages of these methods lie in the delay of responses when using fish, and because it is not possible to extrapolate the results found to the environment once genetically modified organisms are used. In this scenario, we are looking for bioassays that allow a fast and environmentally sound biomonitoring.
\end{abstract}

Keywords: Emerging pollution, Estrogen, Changes in photosynthesis, Changes in behavior.

\section{INTRODUÇÃO}

Existe atualmente uma preocupação crescente quanto à contaminação dos recursos hídricos pelos denominados "poluentes emergentes" (Filho et al., 2007), dentre os quais podem se destacar os advindos de produtos farmacêuticos - como resíduos de medicamentos e seus derivados (Valcarel et al., 2011). Tal situação vem chamando a atenção de pesquisadores, pois ainda se desconhece o potencial ecotoxicológico de tais produtos (Zagatto, 2008). Estes poluentes são encontrados em pequenas quantidades no meio ambiente, o que em princípio não traria complicações imediatas à saúde humana, mas o risco ambiental e as complicações para a saúde humana durante uma exposição crônica precisam ser mais bem avaliados (Kock - Schulmeyer et al., 2011). Tal discussão merece atenção especial porque são escassos, ou, praticamente inexistentes os métodos que removam estes poluentes, sendo as pesquisas nestes campos ainda incipientes, porém promissoras.

Um dos poluentes emergentes que desperta atenção em especial são os estrógenos e seus derivados que se encontram nas águas - principalmente o $17 \alpha$ etinilestradiol e o $17 \beta$ estradiol (Solomon \& Schetller, 2000). Estes hormônios são encontrados em concentrações mínimas, o que de imediato não representa riscos à saúde e ao meio ambiente, porém a exposição crônica pode levar a feminilização de peixes em rios contaminados, e o consumo de águas contaminadas compromete a saúde humana pela ocorrência de um desequilíbrio endócrino (Snyder, 2003), que resulta em uma elevação do risco de desenvolvimento de câncer de colo uterino e de mama em mulheres, e nos homens aumenta a chance de ocorrência de câncer de próstata (Warning, 2005; Maniero et al., 2008). Estes hormônios também exercem ação antioxidante nos organismos vivos devido as suas características químicas, e podem assim influenciar processos metabólicos já existentes (Stancey et al., 1996).

A contaminação dos recursos hídricos por estrógenos e seus derivados vem sendo amplamente estudada, e os esforços atuais se concentram na identificação e remoção química destes hormônios (D'ascenzo et al., 2003). A avaliação da ecotoxicidade promovida pelo estrógeno, valendo-se do uso de biotestes também vem sendo estudada devido à importância de se ter indicadores que permitam haver um parecer sobre a toxicidade aguda e crônica destes hormônios nos ambientes aquáticos.

Para os casos de biotestes que avaliam a contaminação por estrógenos, utilizam-se como biondicadores a vitelogenina (VTG) e a proteína zona 
radiata (ZR). Estes compostos são normalmente encontrados em peixes do gênero feminino, mas quando encontrados em peixes machos juvenis, indicam a ocorrência de desequilíbrio endócrino promovido pela presença de estrógenos no meio (Cordeiro, 2007). Estes biotestes, apesar de serem específicos para a contaminação estrogênica, apresentam como desvantagens a demora em obtenção da resposta, além de um elevado custo para a realização dos testes (Arias, 2007). Tal método ainda requer a captura de peixes, com autorização prévia do IBAMA (Instituto Brasileiro de Meio Ambiente), além de seguir protocolos de proteção animal, o que torna o procedimento ainda mais dificultoso (Azevedo, 2003).

Outro teste utiliza o gene receptor de estrogênio humano integrado ao genoma de uma levedura. No seu interior ocorre a ativação do receptor pelo estrogênio, expressando o gene receptor da Lac-Z que produz a enzima $\beta$-galactosidase. Esta enzima é excretada no meio e metaboliza o substrato cromogênico CPRG (normalmente amarelo) em um produto vermelho, e essa mudança de coloração pode ser medida pela absorbância (Bila, 2007). A desvantagem deste método reside no fato dos seus resultados serem limitados a uma resposta exclusivamente ligada ao receptor estrogênico e da impossibilidade de extrapolação para análise dos resíduos quanto à toxicidade destes ou de risco ambiental.

Com a necessidade de se ter biotestes ágeis e de fácil manuseio, a necessidade de estudo nesta área se torna cada vez mais importante. Mas para credenciar um micro-organismo para uso em biotestes específicos, o mesmo deve ser amplamente estudado, principalmente no que se refere às alterações que podem advir frente à exposição a contaminante. Um dos propósitos deste trabalho é investigar as alterações que podem acontecer com as algas do gênero E. gracilis de uma forma ampla, e verificar sua possibilidade de uso em biotestes que avaliem a eficiência na remoção de estrógenos - pela supressão de certas respostas fisiológicas - e o risco toxicológico dos resíduos originados a partir de processo químicos de descontaminação de estradióis. O micro-organismo E. gracillis - alga unicelular, flagelada, fotrófica e que utiliza diversas fontes de carbono para suas atividades - apresenta parâmetros fisiológicos claros que podem ser afetados na presença de diversos contaminantes. Estes parâmetros são: motilidade, velocidade, velocidade de subida e compactação, dentre outros (Martins, 2008). Outro parâmetro útil também é a atividade fotossintética que estas algas exercem. $O$ problema estudado neste trabalho reside na avaliação de possíveis alterações que ocorrem com estes microorganismos na presença de $17 \alpha$ etinilestradiol e 17 $\beta$ estradiol, visando credenciar este gênero de algas quanto à possibilidade ou não de uso em biotestes de alcance ambiental em trabalhos futuros, seja para a avaliação de amostras com suspeita de contaminação por estes hormônios, seja como marcador de eficiência para processos químicos destinados a remoção de estrógenos, como os processos oxidativos avançados, bem como a avaliação de ecotoxicidade residual dos produtos residuais originados a partir da remoção química do estrógeno e seus derivados.

\section{MATERIAIS E MÉTODOS}

Tratou-se de um estudo experimental, envolvendo o uso de algas do gênero Euglenas gracillis KLEBS, obtidas da coleção da Universidade de Gottingan, Alemanha. Estas algas foram avaliadas quanto às alterações na atividade fotossintética quando submetidas ao contato com os hormônios anteriormente citados, com análises feitas em diferentes tempos de exposição, em meio que continha ainda acetona como fonte de carbono.

Os testes foram realizados com cepas de Euglenas gracilis em meio mineral e orgânico preparado conforme descrição feita por Checcucci et al. (1976). A manutenção da cultura ocorreu sob exposição à luz $20 \mathrm{~W} / \mathrm{m}^{2}$, foto período de 12 horas, e temperatura de $20^{\circ} \mathrm{C}$. Todos os testes foram feitos a partir de uma única cultura, que foi fracionada com o intuito de manter as características e evitar desvios relativos a preparos diferentes de meio mineral.

A solução testada foi obtida a partir do padrão de $17 \alpha$ etinilestradiol e $17 \beta$ etinilestradiol, do laboratório Sigma - AECrich $®$. Devido à baixa solubilidade de $17 \beta$-estradiol e de 17 $\alpha$-etinilestradiol em água, e a necessidade de se ter uma fonte de carbono que servisse de parâmetro para os testes, as soluções estoque foram preparadas com concentração de $0,1 \mathrm{mg} / \mathrm{ml}$ de ambos hormônios em acetona e estocadas a $4^{\circ} \mathrm{C}$.

As soluções nas concentrações iniciais desejadas para cada experimento foram então preparadas a partir da solução estoque e de água Mili-Q ultrapura (livre de matéria orgânica, sais e micro-organismos) obtida pelo sistema da Milipore. As concentrações utilizadas para o teste, obtidas a partir da solução estoque, não seguiram os dados existentes na literatura referentes à contaminação no Brasil e no mundo, pois a intenção não foi avaliar o impacto da atividade "in loco", mas sim conhecer a existência ou não de influência significativa dos hormônios em testes controlados. A concentração escolhida foi de $0,005 \mathrm{mg} / \mathrm{ml}$ de cada hormônio por atender as técnicas exigidas para os testes realizados. O preparo destas soluções foi realizado em uma farmácia de manipulação que atendia os requisitos de biossegurança na manipulação destes 
compostos. O solvente escolhido foi a acetona P.A.; com densidade $0,785 \mathrm{~g} / \mathrm{ml}$ (Laboratório Cinética $\left.{ }^{\circledR}\right)$, devido a sua boa solubilidade dos hormônios neste reagente e por ser este uma conhecida fonte de carbono para as algas. A diluição seguiu o seguinte procedimento: pegou-se $10 \mathrm{ml}$ da solução estoque e dilui-se a mesma em $190 \mathrm{ml}$ de água, obtendo-se uma concentração final de hormônio de $0,005 \mathrm{mg} / \mathrm{ml}$. A concentração final de acetona passou a ser 39,25 $\mathrm{mg} / \mathrm{ml}$. Esta solução é a que foi empregas nos testes na presença de Euglenas. gracilis.

\section{Preparação dos meios de cultura}

As culturas foram preparadas e mantidas em uma única cultura de $400 \mathrm{ml}$, tratadas durante um período de uma semana a fim de se manter homogeneidade do meio para a aplicação dos testes futuros. Esta cultura foi subdivida em 8 frações de $50 \mathrm{ml}$, que receberam posteriormente a adição da solução dos hormônios testes. A adição dos hormônios atendeu o seguinte procedimento: inicialmente dividiu-se em dois frascos, um contendo a solução de estoque de $17 \alpha$ etinilestradiol e outro com $17 \beta$ estradiol onde foram retirados $0,5 \mathrm{ml}$ de cada solução, para a adição em seguida de $0,5 \mathrm{ml}$ de cada cultura, perfazendo um volume final de $50 \mathrm{ml}$ para cada cultura, com concentração de hormônios de $0,0001 \mathrm{mg} / \mathrm{ml}$ e de 0,785 $\mathrm{mg} / \mathrm{ml}$ de acetona. Obteve-se no final: duas amostras para controle, duas para o meio contendo apenas acetona $0,785 \mathrm{mg} / \mathrm{ml}$, duas para o meio contendo $17 \alpha$ etinilestradiol $0,0001 \mathrm{mg} / \mathrm{ml}$ e acetona $0,785 \mathrm{mg} /$ $\mathrm{ml}$, duas para o meio contendo $17 \beta$ estradiol 0,0001 $\mathrm{mg} / \mathrm{ml}$ e acetona $0,785 \mathrm{mg} / \mathrm{ml}$. Os ensaios seguintes foram realizados em duplicatas.

Os testes agudos foram realizados segundo cronograma proposto por Ekelund et al. (2008), no qual se tem uma avaliação imediata dos resultados, a fim de se verificar alguma reação imediata, 1 hora após; com intuito de verificar uma reação inicial mais tardia, a qual não teve resultados; 24 horas após e 7 dias, para verificar possíveis efeitos e adaptações frente a presença de contaminantes (Ekelund et al., 2008), o qual teve resultados.

\section{Avaliações comportamentais das algas pelo biomonitoramento via NG TOX.}

Os experimentos comportamentais com Euglenas gracilis na presença de hormônios foram realizados utilizando uma ferramenta de biomonitoramento em tempo real chamada NG-TOX, desenvolvida e homologada pela Ecobabitonga Tecnologia Ltda (Erzinger et al., 2011). A ferramenta monitorou, através de análise de imagem em tempo real, em um uma sala contendo condições adequadas de temperatura e luminosidade para a avaliação - idênticas ao do cultivo - o comportamento das algas, usando diferentes parâmetros de movimento do flagelado unicelular fotossintetizante.

O equipamento é constituído por um sistema de conexões envolvendo quatro tubos de silicone responsáveis pela sucção da (1) cultura de células de E. gracillis, (2) amostra de águas contendo hormônios para o teste, (3) água para diluição das amostras e (4) descarte do material analisado. Três bombas acionadas por motores de passo peristáltico transportam as células, o diluente e a amostra até uma cubeta de vidro de $22 \mathrm{~mm}$ de diâmetro interno e $0,2 \mathrm{~mm}$ de espessura, que apresenta iluminação para avaliação do parâmetro envolvendo a fototaxia. Os organismos teste, em contato com o diluente são homogeneizados e enviados para uma cubeta de observação, conectada a um microscópio, que captura as imagens das células em movimento (Figura 01). As imagens são gravadas por uma câmara CCD (charged coupled device) e digitalizadas por uma placa conectada a um microcomputador, onde são apresentadas em um monitor (Figura 02). O software então calcula os parâmetros de movimento, velocidade de locomoção, velocidade de subida a superfície, tamanho médio das células; entre outros parâmetros (Häder, 1985). Em seguida é feita a adição das amostras e após um período de 10 minutos é refeita a análise dos parametros pelo software. Qualquer alteração nos movimentos, velocidades médias, velocidades de súbida a superfície e tamanho celular são calculadas e comparadas com a análise anterior.

\section{Analise da alteração na atividade fotossintética}

A fotossíntese das algas é usada como parâmetro ecológico nos testes de bioensaio para monitorar qualidade da água, uma vez que responde com sensibilidade às mudanças ambientais, através de uma variedade de mecanismos que influenciam a eficiência de captação de luz (Belshe et al., 2007).

Parâmetros de fotossíntese serão medidos através de um fluorímetro de amplitude de pulso modulada - PAM 2000, WALZ, EFFELTRICH, Alemanha. O princípio de medição do PAM é baseado em mudanças no nível de fluorescência da clorofila, após a aplicação de pulsos de luz saturada. O rendimento de fotossíntese bem como de têmpera (fotoquímico e não fotoquímico) foram então calculados. As culturas testadas foram adaptadas no escuro por 1 hora, sendo que em seguida foram retirados cerca de $5 \mathrm{ml}$ e transferidos para cubeta do equipamento PAM. Foram submetidas à emissão de 10 pulsos de luz saturante para avaliação da atividade fotossintética.

Em seguida, os dados foram plotados contra o PAR incidente (radiação fotossinteticamente ativa em $\mathrm{mol} \mathrm{m}^{-2} / \mathrm{s}$ ). Desta forma, foi analisada a interferência 
que os hormônios promoveram na Eficiência (Yeld).

Todos os testes foram realizados sempre no mesmo horário, respeitando-se o tempo de exposição à luz das algas na incubadora, onde se encontravam armazenadas.

\section{Analise estatistica:}

As diferenças são então calculadas pelo software ImagingTox $®$, que realiza as análises estatísticas por meio de um programa especialmente desenvolvido e escrito em plataforma Microsoft. Net

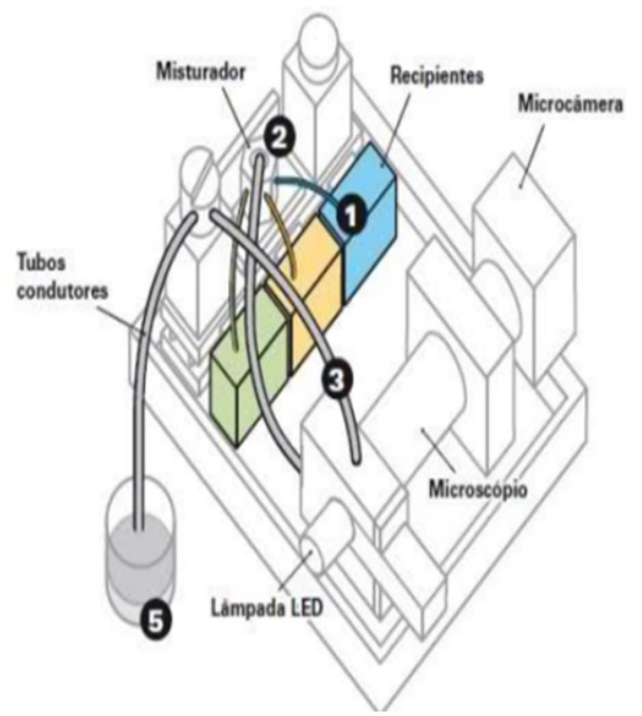

64-bit multilíngue e banco de dados MS SQL Server. Possui sete threads (sendo uma principal, três para vídeo 1 e três para vídeo 2), dois serviços (um para controle de conexão PC e NG-TOX, e um de conexão e validação com o banco de dados), permitindo armazenamento de bioensaios realizados para "análise forense" e tela de exibição de resultados em tempo real. Os dados e informações obtidos e armazenados são criptografados. O ImagingTox $®$ realiza análise estatística 5-PL integrada.

Figura 01 - Esquema de funcionamento do NG TOX.

1 Os pesquisadores separam quatro recipientes:

Com água pura.

Com micro-organismos.

Com amostra

a ser analisada.

Recipiente para receber o resíduo de água.
2 Os três liquidos (amostra, água com algas e água pura) são misturados mecanicamente.

(3) O resultado da mistura é canalizado para um tubo ligado a uma microcâmera $\mathrm{e}$ uma lâmpada led, que garante iluminaçăo para que a câmera registre a movimentação dos micro-organismos.

(4) A imagem da microcâmera é observada numa tela de computador. Além da imagem gerada na tela, um software interpreta a reaçâo dos microorganismos em tempo real, gerando números e gráficos.

5 resto da água misturada é descartado em um recipiente.

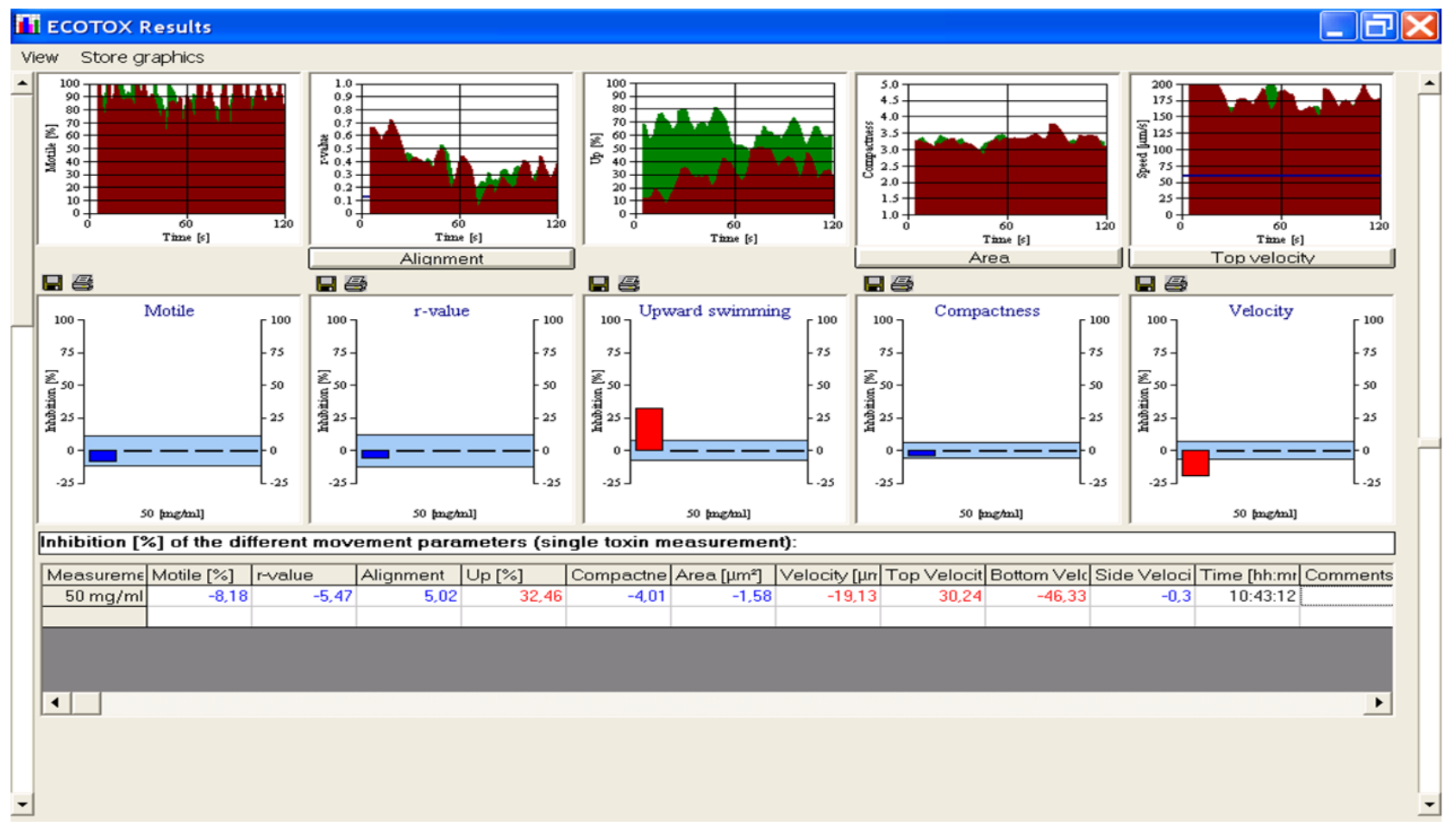

Figura 02 - Imagem do software. 


\section{RESULTADOS}

\section{Análise da velocidade média celular das algas}

Em ambos os períodos analisados, para as condições testadas, observa-se uma inibição significativa da velocidade média das algas, exceto para a exposição a 17 a etinilestradiol no período de 24 horas (Figura 03). Tanto na exposição a 17 a etinilestradiol,

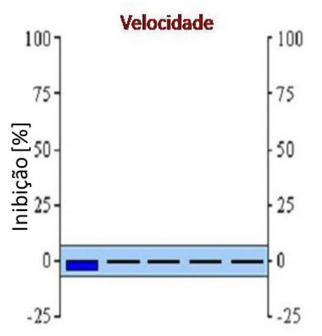

TESTE 24 HORAS

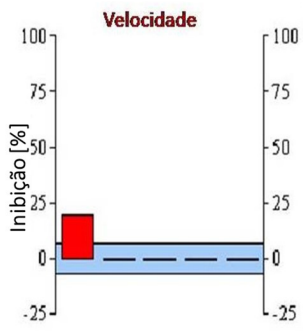

TESTE 7 DIAS
Figura 03 - Inibição da velocidade média celular frente à exposição ao hormônio 17 a etinilestradiol 24 horas e 7 dias após exposição ao hormônio. Barra em vermelho indica alteração significativa $(P<0,005)$. Gráficos gerados pelo sistema ImagingTox. Teste realizado em duplicata.

quanto a exposição a $17 \beta$ estradiol, foi observada uma inibição mais acentuada no sétimo dia, quando comparado com a análise do primeiro dia. O hormônio 17 $\beta$ estradiol foi o que apresentou inibição mais intensa quando comparado com as demais condições (Figura 04). A inibição da velocidade pode servir como um

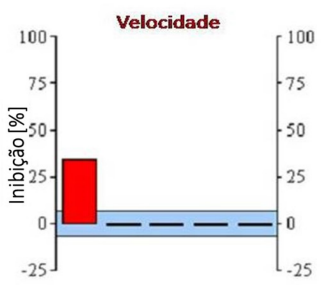

TESTE 24 HORAS

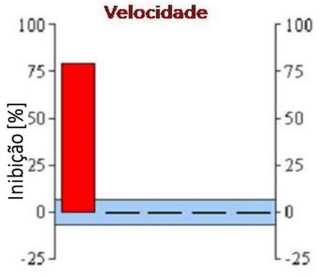

TESTE 7 DIAS
Figura 04 - Inibição da velocidade média celular frente à exposição ao hormônio $17 \beta$ estradiol 24 horas e 7 dias após exposição ao hormônio. Barra em vermelho indica alteração significativa $(P<0,005)$. Gráficos gerados pelo sistema ImagingTox. Teste realizado em duplicata.

indicador de toxicidade, pois significa uma influência sobre o uso de energia da célula ou o metabolismo em geral. Segundo Fujita et al. (2008), a abundância de fontes de carbono leva a um aumento da taxa fotossintética e a um aumento do crescimento celular; fenômenos estes conhecidos para glicose e etanol. No caso da acetona, solvente dos hormônios utilizados, a ação é nociva quando administradas em grandes quantidades, e uma ação moderada é esperada em pequenas quantidades (Stancey et al., 1996; Fujita et al., 2008). Nos experimentos realizados, nota-se que a inibição da velocidade foi maior nos grupos que continham hormônios diluídos em acetona, superando tanto o controle quanto o meio que continha apenas acetona. Tal inibição pode ser devido a estrutura química dos hormônios serem mais complexas e de difícil utilidade como fonte de carbono, necessitando de etapas de metabolização até a sua utilização como tal fonte. Outro aspecto a considerar é a lipofilía dos compostos estrogênicos, que uma vez armazenados podem dificultar a locomoção das células, primeiro pelo volume que ocupam, e segundo pelo fato de não serem as melhores fontes e estarem ocupando um lugar de uma fonte de carbono mais ideal ao metabolismo celular da alga. Tal observação se suporta pelos resultados obtidos na exposição das algas frente a $17 \beta$ estradiol, mais lipofílico e que apresentou maior inibição.

\section{Análise da velocidade média de subida à superfície das algas}

A análise referente ao comportamento de movimento para a superfície das algas demonstrou alterações significativas em ambas as condições, de forma superior ao controle e ao meio contendo apenas acetona (Figura 05 e 06). Tal alteração levantou a

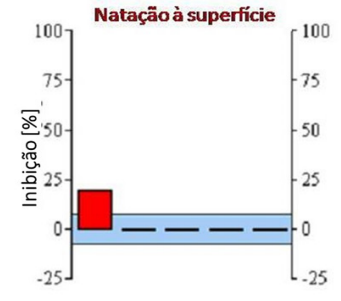

TESTE 24 HORAS

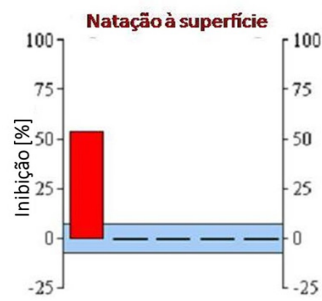

TESTE 7 DIAS
Figura 05 - Inibição da velocidade média de subida à superficie frente à exposição ao hormônio 17 a etinilestradiol 24 horas e 7 dias após exposição ao hormônio. Barra em vermelho indica alteração significativa $(P<0,005)$. Gráficos gerados pelo sistema Imaging Tox. Teste realizado em duplicata.

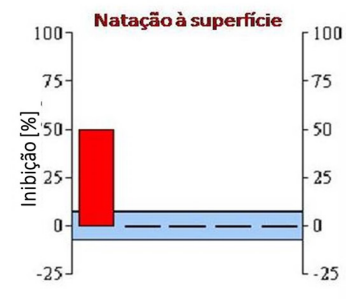

TESTE 24 HORAS

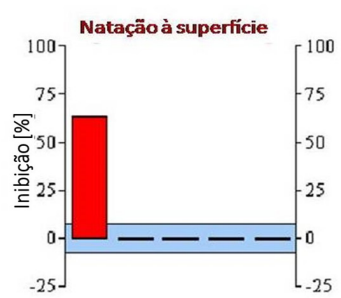

TESTE 7 DIAS
Figura 06 - Inibição da velocidade média de subida à superficie frente à exposição ao hormônio $17 \beta$ estradiol 24 horas e 7 dias após exposição ao hormônio. Barra em vermelho indica alteração significativa $(P<0,005)$. Gráficos gerados pelo sistema ImagingTox. Teste realizado em duplicata.

posição crônica destes hormônios as algas possam sofrer algum tipo de alteração de caráter toxico. Tal parâmetro necessita de uma avaliação mais criteriosa de longo prazo. 


\section{Análise da eficiência fotossintética no período de 7 dias de exposição}

Com intuito de avaliar que as alterações ocorri- das não se davam apenas devido a questão de fluidez, a análise da eficiência fotossintética foi realizada, no qual se obteve os resultados expresso na Figura 07:

$F(3,60)=122,16, p<0,001$

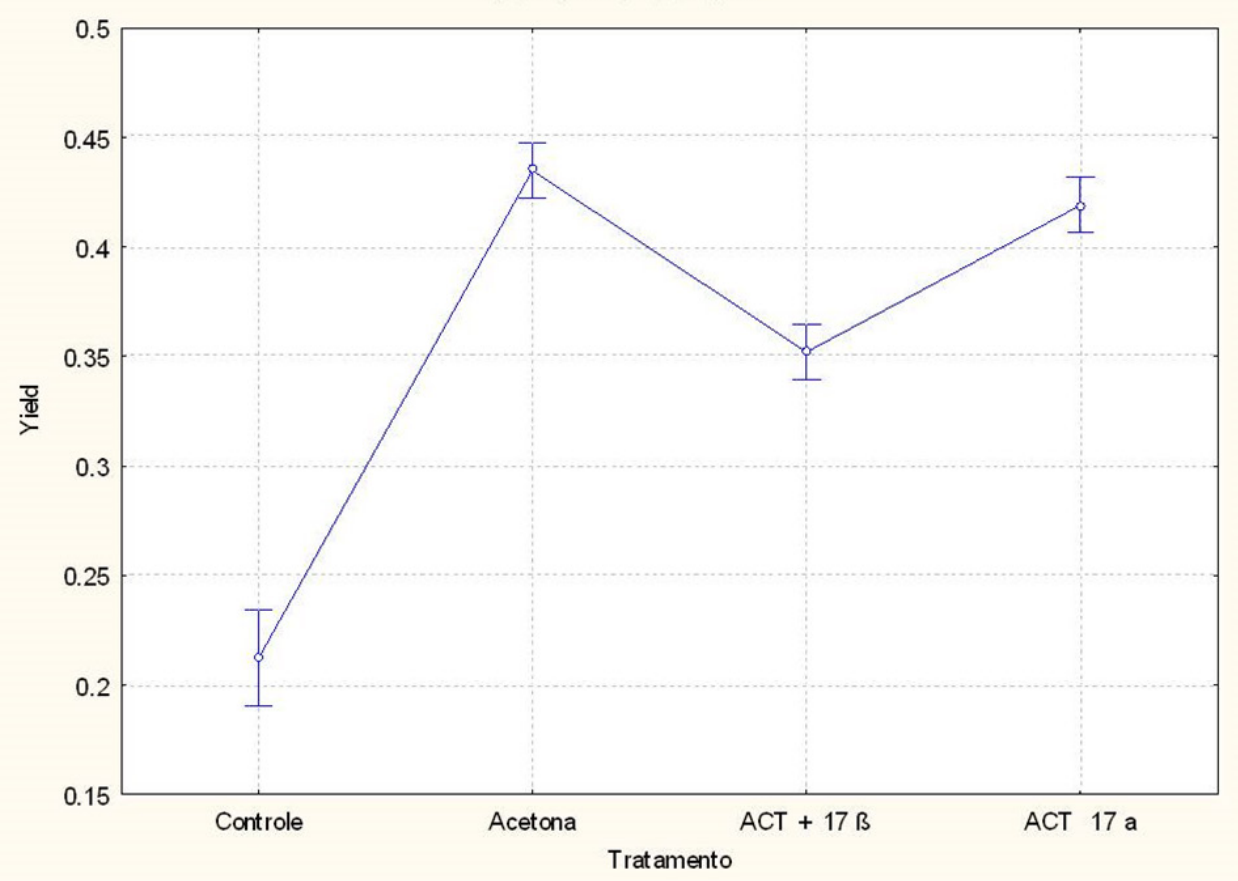

Figura 07 - Comparação das eficiências fotossintéticas médias para os tratamentos $(F(3,60)=122,16, p<0,001)$, teste 7 dia depois da adição, e uma hora no escuro. As barras denotam intervalo de confiança de $95 \%$ em torno da média. Há diferenças entre as médias dos diferentes tratamentos, em relação às menores médias observadas para controle e ACT+17b, a maior média observada foi a do tratamento acetona.

\section{DISCUSSÃO}

Nota-se que neste teste realizado, a eficiência fotossintética no período de 24 horas não foi expressivo, porém nos testes feitos após 7 dias, as algas expostas ao hormônio $17 \beta$ estradiol apresentou uma eficiência menor que o meio exposto apenas a acetona e ao que esteve em contato com $17 \alpha$ etinil estradiol. Considerando que as três circunstâncias havia presença do solvente acetona, nota-se que o comportamento com $17 \beta$ estradiol apresentou característica diferente dos demais, indicando a influência desse hormônio, que pode ser explicado pela ação que este exerceu sobre a habilidade de natação a superfície, que conhecidamente influi sobre a busca de luz e realização de fotossíntese. As alterações nos complexos proteína-pigmento, bem como a diminuição da atividade de fotossíntese, e a inibição da transferência de elétrons são sintomas comuns quando se tem uma situação adversa ao desenvolvimento das algas que promova um estresse (Riviers, 2006). O Fotossistema II (FS II) e o complexo de água-oxidante são os locais sensíveis às condições de estresse e de alterações na atividade (Plekhanov \& Chemeris, 2008).

Uma hipótese para redução da eficiência fotos- sintética seria a redução da atividade antioxidantes do composto $\alpha$ - tocoferol - que desempenha papel fundamental na fotossíntese - pela ação competitiva de compostos com potencial antioxidante reduzido, caso de 2 - hidroxi - estradiol e 4 - hidroxi - estradiol (Cavalieri et al., 2000). Pesquisa realizada por Stacey (1996) procurou comparar a atividade antioxidante de $17 \beta$ - estradiol com outros antioxidantes solúveis em lipídeos ( $\alpha$ - tocoferol e $\beta$ - caroteno). Evidenciou-se neste estudo que o estradiol foi tão eficaz como agente antioxidante quanto ao $\alpha$ - tocoferol, em termos de peroxidação de ácidos graxos. Com comprometimento das atividades antioxidantes por presença de composto com pouco potencial antioxidante, as funções fisiológicas das algas não conseguem impedir a decomposição oxidativa de clorofila, das membranas lipídicas e das proteínas sensíveis a espécies reativas de oxigênio (EROs) (Pinto et al., 2014).

\section{CONCLUSÕES}

Em uma avaliação geral, notou-se que o comportamento das algas frente à exposição dos hormônios implicou em alteração de alguns parâmetros os quais foram significativamente modificados, 
como velocidade e velocidade de subida à superfície. Tais mudanças ocorreram principalmente na presença de $17 \beta$ estradiol, apontando que tais mudanças comportamentais não implicam em toxicidade, mas sim em condições que podem sugerir toxicidade em longo prazo.

Mesmo sendo mudanças de comportamento importante para a alga - como a subida à superfície e comprometimento da fotossíntese - a confirmação de toxicidade a longo prazo só poderá ser avaliada em estudos complementares, visto a alga pode se adaptar às condições e ter um comportamento adequado novamente.

Sendo assim, os dados encontrados foram importantes para questões envolvendo biomonitoramento, indicando a possibilidade de riscos, o que contribui para esta problemática, visto que há uma carência de testes de biomonitoramento para poluentes emergentes. Os estudos demonstraram que estes hormônios, nas concentrações utilizadas, não apresentaram risco e toxicidade aguda para as algas.

Estudos com outros gêneros de algas como Scenedesmus subspicatus podem trazer melhores compreensões sobre a influência dos IEs sobre a atividade fotossintética e outros parâmetros não avaliados neste trabalho.

\section{AGRADECIMENTOS}

Agradecemos ao Departamento de Farmácia, pelo apoio nesta etapa.

Agradecemos ao CNPQ, pelo auxílio de fomento deste projeto através da chamada universal.

\section{REFERÊNCIAS}

Arias, A.R.L.; Buss, D.F.; Albuquerque C.; Inacio A.F.; Freire, M.M.; Egler, M.; Mugnal, R.; Baptista, D.F. 2007. Utilização dos bioindicadores na avaliação de impacto e no monitoramento da contaminação de rios e córregos por agrotóxicos. Ciência e Saúde Coletiva 12 (1). p. 61-72

Aronsson, K. A.; Eckelund, N. G. A. 2005. Effects on motile factors and cell growth of Euglena gracilis after exposure to wood ash solution: assentment of toxicity, nutrient, availability and $\mathrm{pH}$-dependency. Water, Air and Soil Pollution, v.162, p.353-368.

Azevedo, F. A.; Chasin, A. A. M. 2003. As Bases Toxicológicas da Ecotoxicologia. São Paulo: Intertox.

Bila, D. M., Montalvão, A. F., Azevedo, D. A., Dezotti, M. 2007. "Estrogenic Activity Removal of $17 \beta$-Estradiol by Ozonation and Identification of
by-Products", Chemosphere, v. 69, pp. 736-746.

Cavalieri, Ercole; Frenkel, Krystyna; Liehr, Joachim; Roy, Deodutta. Estrogens as Endogenous Genotoxic Agents-DNA Adducts and Mutations. Journal of the National Cancer Institute Monographs, 27:75-93, 2000.

Checcucci, A., Colombetti, G., Ferrara, R. And Lenci, F. 1976. Action spectra for photoaccumulation of green and colorless Euglena: evidence for identification of receptor pigments. Photochem. Photobiol. 23, 51-54.

Cordeiro, D. 2007. Uso de bioindicador de efeito endócrino e validação do método para determinação de hormônios na água da Represa Municipal de São Municipal de São José. Dissertação de Mestrado. Instituto de Química de São Carlos. Universidade de São Paulo. São Carlos.

D'ascenzo, G., Di Corcia, A., Gentili, A., Mancini, R., Mastropasqua, R., Nazzari, M., Samperi, R. 2003. "Fate of Natural Estrogen Conjugates in Municipal Sewage Transport and Treatment Facilities", The Science of the Total Environment, v. 302, pp. 199-209.

Ekelund N.G.A, Nilsson L. April 2008. Effects of estrogenic substances on the movement of Euglena gracillis Verh. Internat. Verein. Limnol. 2008, vol. 30, Part 2, Stuttgart.

Erzinger, G.S., Del Ciampo, L., \& Häder, D.P. 2011. Equipamento e Processo para Análise de Toxicidade em Sistemas Aquáticos. Instituto Nacional de Propriedade Industrial - INPI. No. 0000221105523696.

Filho, R. W. R; Santos, R. L; Vieira, E. M. 2007. Poluentes emergentes como desreguladores endócrinos. J. Braz. Soc. Ecotoxicol., vol.2, n3, 283-288.

Fujita, T.; James C. Hideo T. 2008. Effects of reactive oxygen species on a-tocopherol production in mitochondria and chloroplasts of Euglena gracilis J Appl Phycol (2009) 21:185-191.

Häder, D-P.; Lebert, M. 1985. Real time computer controlled tracking of motile microorganisms. Photochemistry and Photobiology, v. 42, p. 509-514.

Kock - Schulmeyer, M; Ginebreda, A.; Postigo, C; Lopez-Serna, R.; Perez, S.; Brix, R.; Llorca, M.; Lopez De Alda, M.; Petrovic, M.; Munné, A., Tirapu, L. Wastewater reuse in Mediterranean semi-arid areas: The impact of discharges of tertiary treated sewage on the load of polar micro pollutants in the Llobregat river (NE Spain). Chemosphere, 82 (2011) $670-678$.

Maniero M. G.; Bila D. M.; Dezotti M. 2008. Degradation and estrogenic activity removal of $17 \beta$ - estradiol and 17 a-ethinylestradiol by ozonation and 03/ 
PINTO, L.H., et al. (2016). Influência de estradióis sobre atividades de E. gracilis.

H202. Science of the Total Environment, vol. 407, p. $105-115$.

Martins W. 2008. Energy metabolism among eukaryotic anaerobes in light of Proterozoic ocean chemistry. Phil. Trans. R. Soc. B, 363:2717-2729.

Pinto LH ; Kruger, V. ; Steinbach, H. ; Schulter, L. S. ; Sierth, R. ; Ciampo, L. ; Enziger G S . Avaliação do risco de potencial ecotoxicológico de resíduos de $17 \beta$ estradiol obtidos pós-processo oxidativo a base de peróxido de hidrogênio. Revista de Ciências Farmacêuticas Básica e Aplicada, v. 35, p. 435, 2014.

Plekhanov, S. E. And Chemeris, Y. K. Early effect of sodium pentachlorophenate on photosynthetic activity of the alga Chlorella pyrenoidosa Chick. S-39. Plant Physiol. 35, 248-254; 2008.

Reviers, B. 2006. de. Biologia e filogenia das algas. Porto Alegre: Artmed, Silva, Carla G. A. da; Collins, C. H. 2011. Aplicações de cromatografia líquida de alta eficiência para o estudo de poluentes orgânicos emergentes. Química Nova, vol.34, n.4. São Paulo.

Snyder, S. A.; Westerhoff, P.; Yoon, Y.; Sedlak, D. 2003. "Pharmaceuticals, Personal Care Products, and Endocrine Disruptors in Water: Implications for the Water Industry", Environmental Engineering Science, v. 20, n. 5, pp. 449-469.

Solomon, G.; Schettler, T. 2000. "Environment and Health: 6. Endocrine Disruption and Potential Human Health Implications", Canadian Medical Association Journal, v. 163, n. 11, pp. 1471-1476.
Stacey A.; Maoyun T.; M. T. Ravi S. October 1996. Estradiol-17 $\beta$ as an antioxidant: Some distinct features when compared with common fat-soluble antioxidants. The Journal of Laboratory and Clinical Medicine. Volume 128, Issue 4 , Page A1.

Valcárcel, Y; González Alonso, S; rodriguez-Gil, J. L.; Romo R; Gil, A; Catalá, M. 2011. Analysis of the presence of cardiovascular and analgesic/ anti-inflammatory/antipyretic drugs in fluvial and drinking water of the Madrid Region in Spain. Chemosphere. 82 (7), 1062-1071.

Waring, R. H., Harris, R. M. 2005. "Endocrine disrupters: A human risk?", Molecular and Cellular Endocrinology, v. 244, pp. 2-9, 2005. Westerhoff, P., Yoon, Y., Shyder, S., Wert, E. "Fate of Endocrine-Disruptor, Pharmaceutical, and Personal Care Product Chemicals during Simulated Drinking Water Treatment Processes", Environmental Science and Technology, v. 39, pp. 6649-6663.

Zagatto, P. A. Ecotoxicologia. In: Zagatto, P. A.; Bertoletti, E. 2008. (Eds.) Ecotoxicologia aquática: princípios e aplicações. 2. ed. São Carlos: RiMa, 486p. p. 1-13.

Submetido: Abril/2015 Revisado: Março/2017 Aceito: Março/2017 